\title{
Adubação fosfatada e potássica na semeadura e a lanço antecipada na cultura da soja cultivada em solo de Cerrado
}

\author{
Phosphate and potassium at sowing and anticipated on soybean \\ grown in soil from Cerrado
}

\author{
Roni Fernandes Guareschi ${ }^{1 *}$; Paulo Roberto Gazolla ${ }^{2}$; \\ Edson Luiz Souchie ${ }^{3}$; Anisio Correa da Rocha ${ }^{3}$
}

\section{Resumo}

O presente trabalho objetivou comparar o comportamento da cultura da soja adubada com fósforo e potássio em semeadura e a lanço antecipada. Para isso foi realizado um experimento em Latossolo Vermelho distroférrico. O delineamento experimental utilizado foi em blocos ao acaso com 6 tratamentos e 4 repetições. Os tratamentos experimentais foram: 1) ausência de adubação; 2) P e K na semeadura; 3) P e K antecipada; 4) P antecipado e K na semeadura; 5) K antecipado e P na semeadura; 6) metade de P e $\mathrm{K}$ antecipada e a outra metade em semeadura. As variáveis analisadas foram: produtividade, número de grãos por vagem, número de vagens por planta e peso de 1000 grãos. Nas condições estudadas, não houve diferença entre a adubação fosfatada e potássica em semeadura e a lanço antecipada para a cultura da soja. Assim, sugere-se optar por aquela forma de aplicação de fertilizante que garanta o menor custo. Palavras-chave: Glycine max, adubação antecipada, fertilizantes, fertilidade do solo

\begin{abstract}
This work aimed to compare the soybean yield when phosphorus and potassium manuring was anticipated or at sowing. The experiment was carried out under field conditions in a dystrophic Red Latosol (Oxisol). A completely randomized block design with six treatments and four replicates was used. The treatments were: 1) no manuring; 2) $\mathrm{P}$ and $\mathrm{K}$ at sowing; 3 ) anticipated $\mathrm{P}$ and $\mathrm{K}$; 4) anticipated $\mathrm{P} ; 5)$ anticipated $\mathrm{K} ; 6)$ half of $\mathrm{P}$ and $\mathrm{K}$ anticipated and the another half at sowing. Yield, weight of 1000 grains, number of grains per pods and number of pods per plant were evaluated at harvest. There was no difference between anticipated and sowing fertilization to soybean. Therefore, the best option to soil fertilization should be that with the lowest cost.
\end{abstract}

Key words: Glycine max, prefertilization, fertilizers, soil fertility

\footnotetext{
1 Graduando de Tecnologia em Produção de Grãos, CEFET - Rio Verde. Bolsista PIBIC / CNPq. Rua Caiapônia, nº 994, Centro, Montividiu, GO, CEP 75915-000. E-mail: roniguareschi@gmail.com

2 Graduando de Tecnologia em Produção de Grãos, Centro Federal de Educação Tecnológica de Rio Verde-GO.

3 Prof. Dr. Centro Federal de Educação Tecnológica de Rio Verde, GO.

Autor para correspondência
} 


\section{Introdução}

A soja (Glycine max L. Merril) é uma das culturas que mais produz grãos no mundo sendo cultivada em quase todo o território brasileiro, atingindo altos índices de produtividade (SEGATELLI, 2004). Atualmente, um dos fatores que representam maior custo para o agricultor é o uso de insumos, como os fertilizantes. Dentre as formas de distribuição de fertilizantes, as que se destacam é a adubação de semeadura e a adubação a lanço antecipada. A primeira consiste na aplicação de fertilizantes e sementes ao mesmo tempo na linha de semeadura. O sistema convencional tem sido muito utilizado desde a invenção da semeadora-adubadora que realiza este procedimento favorecendo o manejo das culturas (MALAVOLTA, 1981). A segunda forma consiste em antecipar a aplicação total ou parcial da quantidade de fertilizante requerida, numa cultura de verão, permitindo que o processo de semeadura ocorra de forma mais rápida (CHUEIRI, 2005).

Os atrasos durante a operação de semeadura resultam em decréscimos na produtividade, sendo uma das razões a necessidade de aplicar grandes quantidades de adubos no momento da implantação da cultura. Essas grandes quantidades implicam em maior tempo e número de abastecimentos da semeadora, influenciando na sua capacidade operacional. Portanto, uma das alternativas para contornar o problema é antecipar a adubação. Neste sistema, a adubação é aplicada antes da semeadura, proporcionando um menor tempo nas paradas para o abastecimento da semeadora, redução do número de conjuntos, dos custos operacional e total, possibilitando, desta forma, aumento na receita líquida se comparado ao sistema tradicional, independentemente do período de semeadura (MATOS; SALVI; MILAN, 2006). Esta técnica tem sido bastante utilizada no Brasil, porém são poucos os estudos que relatam sua eficiência em relação a outras técnicas de adubação (SEGATELLI, 2004).

O objetivo deste trabalho foi comparar a produtividade da cultura da soja adubada com fósforo $(\mathrm{P})$ e potássio $(\mathrm{K})$ em semeadura e a lanço antecipada em Latossolo Vermelho distroférrico.

\section{Material e Métodos}

O experimento foi realizado na área experimental do Centro Federal de Educação Tecnológica de Rio Verde, no Sudoeste de Goiás, localizada a $17^{\circ} 47^{\prime}$ e 53" de latitude Norte e $51^{\circ} 55^{\prime} 53$ " de latitude Sul, a $743 \mathrm{~m}$ de altitude, predominantemente com Latossolo Vermelho distroférrico. Foi feita a análise da fertilidade e textura do solo, constatando-se os seguintes valores: $\mathrm{pH}$ (em água) $=6,3 ; \mathrm{C}_{\text {org }}=30,1$ (g $\left.\mathrm{dm}^{-3}\right) ; \mathrm{P}_{\text {(Mehlich I) }}=8,7 \mathrm{mg} \mathrm{dm}^{-3} ; \mathrm{K}=9,0 \mathrm{mmol} \mathrm{dm}^{-3}$; $\mathrm{Ca}=94 \mathrm{mmol} \mathrm{dm}{ }^{-3} ; \mathrm{Mg}=27,3 \mathrm{mmol} \mathrm{dm}^{-3} ; \mathrm{Al}=0,0$ mmol dm ${ }^{-3} ; \mathrm{V} \%=70,5$ e textura média $(50 \%$ de argila, $12 \%$ de silte e $38 \%$ de areia).

O delineamento experimental foi em blocos casualizados com 6 tratamentos e 4 repetições envolvendo épocas de aplicação dos fertilizantes. Cada parcela foi constituída de 6 fileiras de $4 \mathrm{~m}$ de comprimento, espaçadas de $0,5 \mathrm{~m}$, perfazendo 12 $\mathrm{m}^{2}$ de área total. Como área útil foi considerada as 4 fileiras centrais, excluindo $1 \mathrm{~m}$ de cada extremidade.

Os tratamentos experimentais foram: 1) ausência de adubação; 2) P e K na semeadura; 3) P e K antecipado; 4) $\mathrm{P}$ antecipado e $\mathrm{K}$ na semeadura; 5) $\mathrm{K}$ antecipado e $\mathrm{P}$ na semeadura; 6) metade de $\mathrm{P}$ e $\mathrm{K}$ antecipada e a outra metade em semeadura. A adubação fosfatada ( $90 \mathrm{~kg} \mathrm{ha}{ }^{-1}$ de $\mathrm{P}_{2} \mathrm{O}_{5}$ ) foi feita utilizando superfosfato simples $\left(20 \%\right.$ de $\mathrm{P}_{2} \mathrm{O}_{5}$ e $12 \%$ de $\mathrm{S})$ e a potássica $\left(60 \mathrm{~kg} \mathrm{ha}^{-1} \mathrm{de}_{2} \mathrm{O}\right)$, com cloreto de potássio $\left(60 \%\right.$ de $\left.\mathrm{K}_{2} \mathrm{O}\right)$.

A adubação antecipada foi realizada a lanço (manualmente), 15 dias antes da semeadura. Treze dias após a adubação antecipada, a gleba foi dessecada com glyphosate na dosagem de $4 \mathrm{~L} \mathrm{ha}^{-1}$ ). Dois dias após a dessecação, com um sulcador, foi feita a abertura dos sulcos. Antes da semeadura, as sementes foram tratadas com o fungicida carbendazin e com o inseticida fipronil, ambos na 
dosagem de $800 \mathrm{~mL}$ para $400 \mathrm{~kg}$ de semente de soja. Em seguida, as sementes foram inoculadas com Bradyrhizobium japonicum (125 mL de inoculante líquido para $50 \mathrm{~kg}$ de sementes). A semeadura foi realizada manualmente, distribuindo-se 12 sementes por metro linear no sulco de plantio.

A cultivar de soja utilizada foi a BRS-Valiosa RR, que apresenta ciclo semi - precoce, hábito de crescimento determinado, floração aos 58 dias, maturação aos 124 dias e peso de $100 \mathrm{~g}$ de sementes equivalente a $14,7 \mathrm{~g}$.

No controle de plantas daninhas em pósemergência foi utilizado glyphosate $\left(1,5 \mathrm{~L} \mathrm{ha}^{-1}\right)$, aos 30 dias após a emergência (DAE). Foi também realizado o controle de Diabrotica speciosa com lambidacialotrina $\left(150 \mathrm{~mL} \mathrm{ha}^{-1}\right)$. A partir dos 60 DAE procurou-se identificar focos de ferrugem asiática. Neste período, foi aplicado o fungicida trifloxystrobin + ciproconazole $\left(300 \mathrm{~mL} \mathrm{ha}^{-1}\right)$, preventivamente, uma vez que a doença não foi encontrada. Doze dias após esta aplicação, outra amostragem foi realizada no experimento e constataram-se focos da doença. Efetuou-se então o controle da mesma com o fungicida azoxystrobin + ciproconazole (300 $\left.\mathrm{mL} \mathrm{ha}^{-1}\right)$.

Aos 124 DAE, o experimento foi colhido.
Avaliaram-se número de vagens por planta, número de grãos por vagem, peso de 1000 grãos e rendimento. O número de grãos por vagem foi avaliado pela contagem do número de vagens contendo 1, 2 e 3 grãos em 10 plantas retiradas ao acaso das duas linhas centrais de cada tratamento. Nestas mesmas plantas, foi avaliado o número de vagens.

A produtividade e o peso de 1000 grãos foram estimados na área útil da parcela. Os grãos colhidos na área útil de cada parcela foram beneficiados, pesados e a umidade determinada, corrigida para $13 \%$. Os dados foram submetidos à análise de variância e as médias comparadas pelo teste Tukey a 5\% de probabilidade, utilizando o programa estatístico Sisvar (FERREIRA, 1999).

\section{Resultados e Discussão}

Não foi detectada diferença entre os tratamentos, avaliando-se o peso de 1000 grãos, número total de vagens por planta e número de grãos por vagem. Houve diferença somente para a variável produtividade $\left(\mathrm{kg} \mathrm{ha}^{-1}\right)$, onde $\mathrm{P}+\mathrm{K}$ antecipado superou os tratamentos $\mathrm{P}$ antecipado e testemunha (Figura 1). Também não foi verificada diferença entre os tratamentos $\mathrm{P}+\mathrm{K}$ na forma antecipada $\mathrm{e}$ em semeadura (Figura 1).

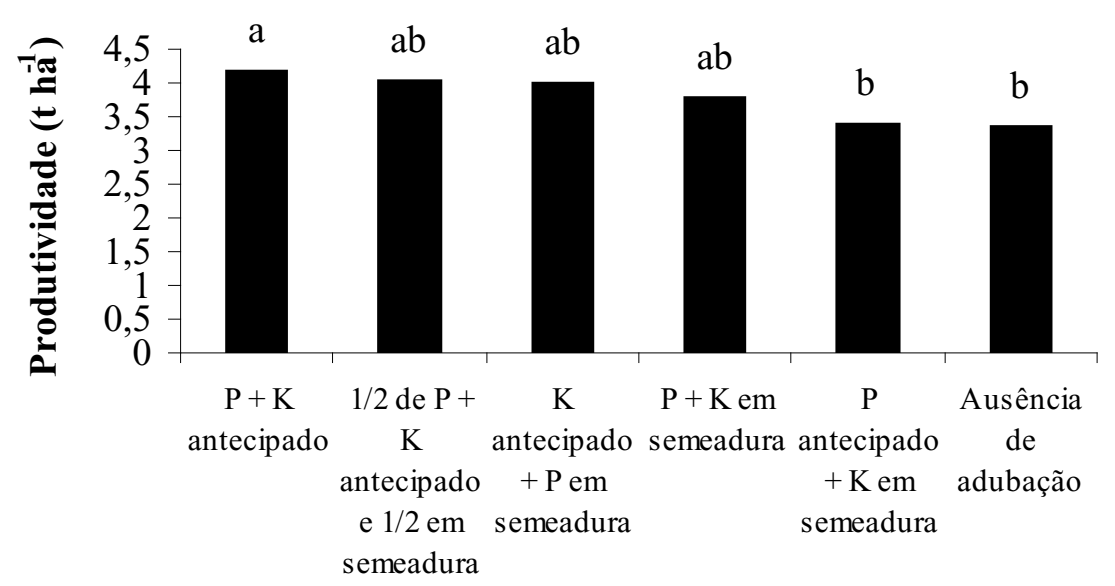

\section{Tratamentos de adubação}

Figura 1. Produtividade da cultura da soja cultivada sob distintas formas de aplicação da adubação fosfatada e potássica. Médias seguidas de mesma letra não diferem entre si pelo teste Tukey (5\%). CV=7,7\%. 
Tendo em vista que, por exemplo, não houve diferença entre os tratamentos: $\mathrm{P}+\mathrm{K}$ antecipado e $\mathrm{P}+\mathrm{K}$ em semeadura, deve-se optar pela forma de adubação de menor custo operacional. Matos, Salvi e Milan (2006) relatam que o sistema de antecipação da adubação para a cultura da soja é viável, reduzindo o número de conjuntos, os custos operacional e total, possibilitando o aumento na receita líquida, quando comparado ao sistema tradicional, independentemente do período de semeadura. Similarmente, Pavinato e Ceretta (2004) verificaram que com a difusão do plantio direto e melhoria na fertilidade dos solos, tem havido maior interesse na distribuição antecipada dos fertilizantes fosfatados e potássicos. Com isso, o produtor consegue maior agilidade na implantação das culturas de verão, melhor utilização de maquinário e mão-de-obra, além de menor custo dos fertilizantes e de seu transporte.

Segundo a EMPRESA BRASILEIRA DE PESQUISA AGROPECUÁRIA - EMBRAPA (2007), a produtividade média da soja brasileira na safra de 2006/2007 foi de $2.823 \mathrm{~kg} \mathrm{ha}^{-1}$, com aplicação de adubação junto à semeadura. Sob o mesmo sistema, a média da produtividade do estado de Goiás, na safra de 2006/2007, foi em torno de $2.790 \mathrm{~kg} \mathrm{ha}^{-1}$ (COMPANHIA NACIONAL DE ABASTECIMENTO - CONAB, 2008). Nas condições deste trabalho, a maior produtividade encontrada foi de $4.182 \mathrm{~kg} \mathrm{ha}^{-1}$, utilizando adubação antecipada e $3.798 \mathrm{~kg}$ ha $^{-1}$ com adubação na semeadura. Observa-se que as produtividades em ambos os sistemas de adubação, alcançadas neste experimento, foram consideravelmente superiores às médias nacional e regional. Atribui-se esses resultados às condições de fertilidade do solo utilizado neste estudo, que geralmente superam os níveis de fertilidade da maioria dos solos da região do Cerrado. Considerando o teor de $\mathrm{P}(8,7$ $\mathrm{mg} \mathrm{dm}{ }^{-3}$ ) e o de argila (50\%) do solo utilizado neste estudo, segundo Sousa e Lobato (2004), este solo apresenta teor adequado de P (8,1 a 12,0 $\left.\mathrm{mg} \mathrm{dm}^{-3}\right)$, estando abaixo somente de solos com níveis de $\mathrm{P}$ considerados altos $\left(>12,0 \mathrm{mg} \mathrm{dm}^{-3}\right)$.
Wiethölter, Ben e Pöttker (1998) consideram plenamente viável realizar uma adubação de préplantio em solos com altos níveis de fertilidade. Tornquist (2001) relata que estudos conduzidos em 69 lavouras de soja em sistema de plantio direto em todo o Brasil, na safra 97/98, demonstraram que a aplicação da adubação antecipada é vantajosa pela melhor distribuição dos nutrientes na área da lavoura, o que favorece um sistema radicular amplo; maior rapidez na semeadura, pela eliminação da necessidade de recarregar com fertilizante as semeadoras, principalmente quando o fertilizante está ensacado. Em grandes propriedades estes fatores permitem significativos ganhos, pois permitem que uma maior área seja plantada na época recomendada. Entretanto, os resultados do presente trabalho, apesar da alta fertilidade do solo utilizado, corroboram os de Lana, Vilela Filho e Zanão Junior (2003), em que a adubação antecipada aplicada até cinco meses antes da semeadura não influenciou no rendimento de grãos da soja, quando comparado com a aplicação de adubação na semeadura. Similarmente, Pöttker (1999) avaliou o efeito do teor de $\mathrm{P}$ do solo sobre a eficiência da adubação na linha de semeadura e a lanço na superfície do solo e concluiu que, para a soja, o modo de aplicação não interferiu no rendimento de grãos.

Segundo Staut e Kurihara (2000) a adubação a lanço antecipada de P é utilizada para aumentar a eficiência da operação de plantio. A adubação a lanço permite que todo o fertilizante fosfatado entre em contato com o solo, o que promove elevada fixação do $\mathrm{P}$ e, conseqüentemente, reduz seu aproveitamento pela planta. Por outro lado, a aplicação no sulco de semeadura, no momento do plantio, diminui a fixação, porém menor área do sistema radicular entra em contato com o P. Para Sousa e Lobato (2004), a aplicação de fertilizantes fosfatados a lanço deve ser utilizada para doses superiores a $100 \mathrm{~kg} \mathrm{ha}^{-1}$ de $\mathrm{P}_{2} \mathrm{O}_{5}$. No caso de doses inferiores para culturas anuais, recomenda-se sua aplicação em sulcos, o que possibilita melhor uso do P do fertilizante solúvel em água, além da praticidade da operação junto à semeadura. 
Amoacy (2006) relata diversos resultados que indicam a viabilidade da adubação fosfatada em superfície, desde que os teores de P no solo estejam em níveis altos, que não haja impedimento à infiltração e que a distribuição das chuvas seja homogênea. Da mesma forma, o $\mathrm{K}$ também pode ser aplicado em superfície. Quando aplicado na linha de semeadura e a dose for superior a $60 \mathrm{~kg}$ de $\mathrm{K}_{2} \mathrm{O}$ ha $^{-1}$, esse fertilizante $(\mathrm{KCl})$ pode causar algum dano, principalmente em sementes de leguminosas, devido ao seu efeito salino. Quando a necessidade de aplicação for alta, em solos com baixa CTC e em áreas sujeitas à precipitação pluvial intensa, como na região dos Cerrados, o K deve ser aplicado a lanço, em doses que permitam a manutenção dos níveis adequados no solo e que reponham as quantidades exportadas pelas culturas.

Sá (2004) relata que a aplicação de fertilizantes fosfatados a lanço, sem incorporação no plantio direto, é uma prática viável como adubação de manutenção e/ou restituição para solos que tenham sido adubados e apresentam teores médios a altos de P. Para solos com baixos teores de P é recomendado adubação em sulco. Broch e Chueiri (2006) avaliando diferentes estratégias de adubação de manutenção para a cultura da soja, em sistema plantio direto, relatam que a aplicação a lanço do fertilizante mostrou-se viável em solos de boa e média fertilidade. No entanto, em solos com baixo teor de $\mathrm{P}$, a adubação a lanço mostrou-se inviável.

\section{Conclusão}

Não houve diferença entre a adubação fosfatada e potássica em semeadura e a lanço antecipada, para a cultura da soja cultivada em solo de Cerrado.

\section{Referências}

AMOACY, F. C. Plantio direto: adubação na superfície ou incorporada? 2006. Disponível em: <www.plantiodireto. com.br/?body=cont_int\&id=419>. Acesso em: 10 jan. 2006.

BROCH, D. L.; CHUEIRI, W. A. Estratégia de adubação cultura da soja cultivada sob sistema de plantio direto. 2006. Disponível em: <www.manah.com.br/publicacoes/ estrategias_abudacao.pdf $>$. Acesso em: 28 jan. 2007.

CHUEIRI, W. Sistema plantio direto e alternativas para adubação. 2005. Disponível em: <www.fundacaoms. com.br>. Acesso em: 10 jan. 2006.

COMPANHIA NACIONAL DE ABASTECIMENTO - CONAB. Acompanhamento da safra 2007/2008 brasileira. 2008. Disponível em: <http://www.conab. gov.br/conabweb/download/safra/estudo_safra.pdf>. Acesso em: 18 jan. 2008.

EMPRESA BRASILEIRA DE PESQUISA AGROPECUÁRIA - EMBRAPA. A soja. 2007. Disponível em: <http://www.cnpso.embrapa.br/index. php?op_page $=22 \&$ cod_pai $=16>$. Acesso em: 18 jan. 2008.

FERREIRA, D. F. Sistema de análise de variância (Sisvar). versão 4.6. Lavras: Universidade Federal de Lavras, 1999. CD-ROM.

LANA, R. M. Q.; VILELA FILHO, C. E.; ZANÃO JÚNIOR, L. A. Adubação superficial com fósforo e potássio para a soja em diferentes épocas em présemeadura na instalação do plantio direto. Scientia Agricola, Piracicaba, v. 4, n. 1-2, p. 53-60, 2003.

MALAVOLTA, E. Manual de química agrícola: adubos e adubação. São Paulo: Agronômica Ceres, 1981.

MATOS, M. A.; SALVI, J. V.; MILAN, M. Pontualidade na operação de semeadura e a antecipação da adubação e suas influências na receita líquida da cultura da soja. Engenharia Agrícola, Jaboticabal, v. 26, n. 2, p. 493-501, 2006.

PAVINATO, P. S.; CERETTA, C. A. Fósforo e potássio na sucessão trigo/milho: épocas e formas de aplicação. Ciência Rural, Santa Maria, v. 34, n. 6, p. 1779-1784, 2004.

PÖTTKER, D. Modos de aplicação de fósforo para uma seqüência de culturas em plantio direto. Revista Plantio Direto, Passo Fundo, v. 53, p. 15, out. 1999. 
SÁ, J. C. M. Adubação fosfatada no sistema plantio direto. In: SIMPÓSIO SOBRE FÓSFORO NAAGRICULTURA BRASILEIRA, 1., 2004, Piracicaba. Anais... Piracicaba: POTAFOS, 2004. p. 201-222.

SEGATELLI, C. R. Produtividade da soja em semeadura direta com antecipação da adubação fosfatada e potássica na cultura da Euleunice coracana. 2004. Dissertação (Mestrado em Fitotecnia) - Universidade de São Paulo, Piracicaba.

SOUSA, D. M. G.; LOBATO, E. Cerrado: correção do solo e adubação. Planaltina: Embrapa Cerrados, 2004.
STAUT, L. A.; KURIHARA, C. H. Embrapa Dourados assume plantio direto. 2000. Disponível em: <www. plantiodireto.com.br/?body=cont_int\&id=31>. Acesso em: 23 jan. 2006.

TORNQUIST, C. G. Aspectos básicos da fertilidade do solo no plantio direto. 2001. Disponível em: <www. manah.com.br/informativos.asp?idI=22>. Acesso em: 20 jan. 2006.

WIETHÖLTER, S. J. R.; BEN, R. A.; PÖTTKER, D. Fósforo e potássio no SPD. In: NUERNBERG, N. Conceitos e fundamentos do sistema plantio direto. Lages: SBCS - Núcleo Regional Sul, 1998. p. 121-149. 